\title{
A OPERAÇÃO DE ADIÇÃo E SUBTRAÇÃo NO ÁBACO ROMANO
}

\section{THE ADDITION AND SUBTRACTION OPERATION IN THE ROMAN \\ ABACUS.}

\author{
Ângela Maria Visgueira Cunha ${ }^{1}$ \\ Universidade Federal do Piauí \\ Wilter Freitas Ibiapina ${ }^{2}$ \\ Universidade Federal do Piauí
}

\begin{abstract}
Resumo
O ábaco é um instrumento que o homem inventou quando precisou fazer cálculos cada vez mais complicados e o usou quando ainda não dispunha dos algarismos indo-arábico. Os ábacos mais comuns foram tábuas ou pranchas com divisões em diversas linhas ou colunas paralelas separando as diferentes ordens de numeração. No ábaco dos romanos antigos, cada uma das colunas enfileiradas simbolizava geralmente uma das potências de base 10. Assim, desenvolvemos uma pesquisa bibliográfica na qual pretendemos mostrar os métodos históricos de adição e subtração no ábaco romano.
\end{abstract}

Palavras-chave: Ábaco. Cálculo. Adição. Subtração.

\begin{abstract}
Abacus is an instrument which humans have invented when they needed to make ever more complicated calculations and used it when they did not have the Indo-Arabic numeration. The most common abacuses were boards or planks with divisions in several lines or parallel columns separating the different numbered orders. On the abacus of the ancient Romans, each lined columns usually symbolized one potency of base 10 . So we developed a bibliographic research in which we intend to show the historic methods of addition and subtraction in the Roman abacus.
\end{abstract}

Keywords: Abacus. calculation. Addition. Subtraction.

\section{Introdução}

O ábaco romano retrata ao início da civilização romana e foi usado de maneira frequente até, pelo menos, o final da Idade Média. Era formado basicamente de uma prancha com várias colunas verticais, onde cada coluna simbolizava um agrupamento

\footnotetext{
1 angelavisgueira@gmail.com

2 wilteribiapina@gmail.com
} 
em potencias de base dez. Os números eram representados por fichas feitas de pedra, vidro ou metal, mas sem haver qualquer imagem.

De acordo com Fossa (2010, p. 279), “o ábaco, na sua forma original, foi certamente um instrumento que permitia computar através da contagem", pois as operações básicas da soma e da subtração no ábaco são semelhantes às operações realizadas em sistemas de agrupamentos simples.

Diante isto, este trabalho visa explanar os métodos históricos de adição e subtração no ábaco com o sistema de numeração romana.

\section{Metodologia}

Esta pesquisa trata-se de uma revisão de literatura. Segundo Lakatos \& Marconi (2005), a revisão de literatura refere-se ao nível de questões específicas a serem integradas pelo pesquisador, também é um trajeto crítico, relacionando-se intensamente com as perguntas pautadas nos objetivos específicos.

Neste tipo de pesquisa, o pesquisador rever os trabalhos acessíveis com o intuito de encontrar materiais relacionados com a questão. A partir dos instrumentos bibliográficos buscou identificar os métodos históricos de adição e subtração no ábaco com o sistema de numeração romana.

\section{Discussão}

\section{Adição}

Há pouca evidência histórica de como as operações eram desenvolvidas no ábaco. Para Fossa (2010), é provável que as primeiras somas no ábaco fossem feitas conforme o exemplo abaixo. Representavam as parcelas no instrumento e depois reagrupavam-nas de acordo com a sua característica.

Exemplo: Adicione 132 a 4563.

Representavam inicialmente no ábaco os dois números. 


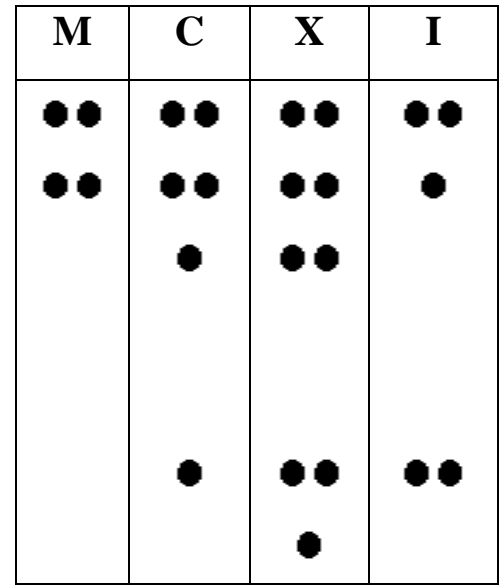

Em seguida, reagrupavam cada coluna adicionando uma parcela a outra. Assim, tem-se.

Unidades: $3+2=5$

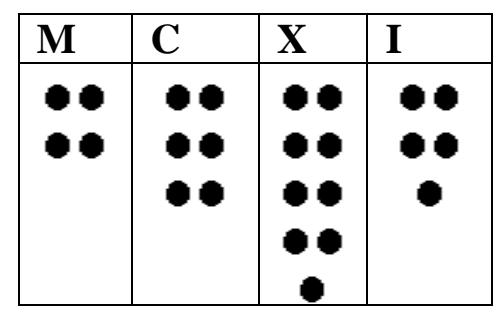

Dezenas: $6+3=9$

Centenas: $5+1=6$

Unidade de milhar: $4+0=0$

Portanto, $4563+132=4695$

Fossa (2010) depois de olhar várias reproduções artísticas antigas de pessoas manipulando o ábaco, observou que o operador estava frequentemente acompanhado por outras pessoas. Assim, conforme o referido autor é provável que ao usar o ábaco, no mínimo, tinha-se o operador (a pessoa que movimenta as fichas), e um assistente (a pessoa que dita o problema e registra o resultado).

Assim, ao realizar a adição de 132 a 4532 o operador realizava da seguinte:

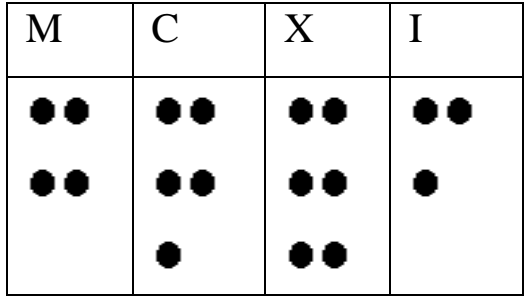

$\mathrm{O}$ assistente anuncia o valor da primeira parcela: "quatro mil, quinhentos e sessenta e três." O operador representa o número no ábaco. 
Depois, o assistente diz: "Soma cento..." pausa, o operador coloca duas fichas na coluna das centenas.

\begin{tabular}{|c|c|c|c|}
\hline $\mathbf{M}$ & $\mathrm{C}$ & $\mathbf{X}$ & I \\
\hline$\bullet$ & 0 & 0 & 0 \\
\hline 0 & 00 & 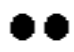 & \\
\hline & & 0 & \\
\hline & & $\bullet$ & \\
\hline & & & \\
\hline
\end{tabular}

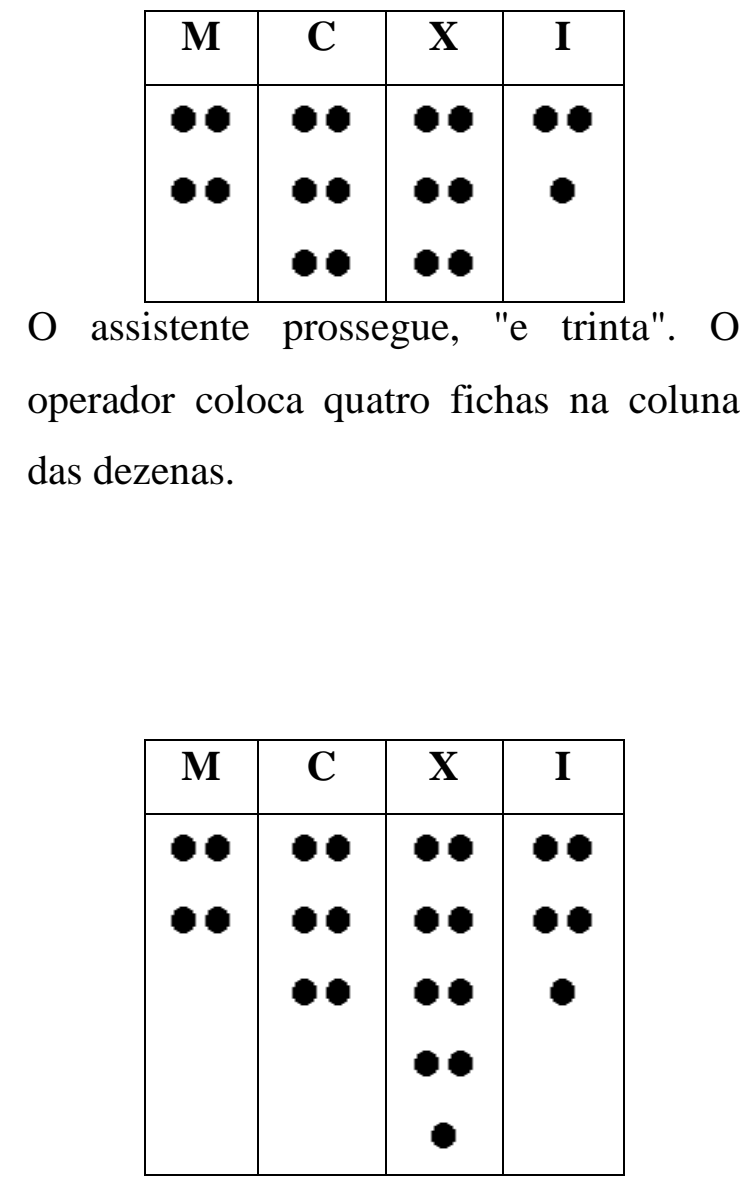
operador coloca quatro fichas na coluna das dezenas.

Prosseguindo, o assistente diz: "e dois".

Coloca-se cinco fichas na coluna das unidades.

\section{Subtração}

A subtração era feita de modo análogo a adição.

Fazendo 6537 - 132, tem-se:

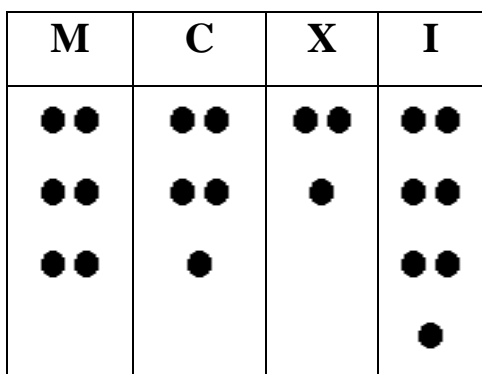

$\mathrm{O}$ assistente anuncia o valor do minuendo

e o operador representa o número no ábaco.

\begin{tabular}{|c|c|c|c|}
\hline $\mathbf{M}$ & $\mathbf{C}$ & $\mathbf{X}$ & I \\
\hline & $\bullet$ & & 0 \\
\hline
\end{tabular}

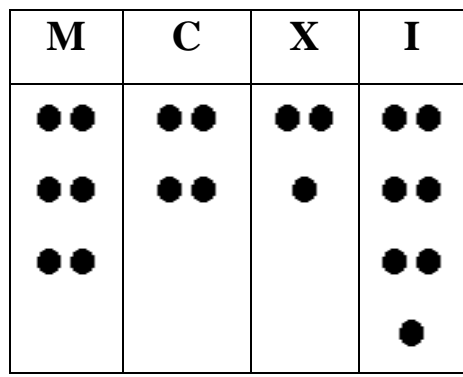

O assistente prossegue, "e trinta...". O operador retira duas fichas na coluna das 


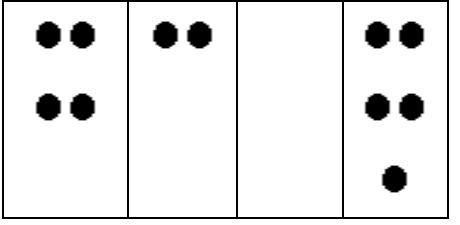

Prosseguindo, o assistente diz: "e dois...". Remove-se uma ficha na coluna das unidades. dezenas.

\begin{tabular}{|c|c|c|c|}
\hline $\mathbf{M}$ & $\mathrm{C}$ & $\mathbf{X}$ & I \\
\hline$\bullet$ & 00 & & $\bullet$ \\
\hline$\bullet$ & 0 & & $\bullet$ \\
\hline 0 & & & $\bullet$ \\
\hline
\end{tabular}

\section{Considerações finais}

Como se percebe, a adição e subtração não era muito trabalhosa, e o manuseio era semelhante com o algoritmo destas operações usadas hoje. Para Fossa (2010), as decomposições que a gente atualmente entenderia como justificadas pela notação posicional não foram justificadas dessa maneira pelo operador do ábaco. Foram resultados de experiência prática em operar com o ábaco.

\section{Referências}

FOSSA, J. A. Os primórdios da teoria dos números. Natal: EDUFRN, 2010. (Arquivo para a história da teoria dos números e da lógica, v. 1, parte A).

LAKATOS, E. M.; MARCONI, M. A. Fundamentos de metodologia científica. 7. ed. São Paulo: Atlas S.A, 2010. 